\title{
Incidência de stress e fontes estressoras em esposas de portadores da síndrome de dependência do álcool
}

\author{
Incidence of stress and stressful sources in alcoholics' wives
}

\author{
Raitza Araújo dos Santos LIMA' \\ Maria Cristina Lopes de Almeida AMAZONAS² \\ Juliana Amazonas Gouveia MOTTA ${ }^{3}$
}

\begin{abstract}
Resumo
Esta pesquisa investigou a incidência de stress e suas fontes em esposas de portadores da síndrome de dependência do álcool, utilizando o Inventário de Sintomas de Stress de Lipp e uma entrevista semi-estruturada com 31 mulheres de maridos atendidos em uma clínica para dependentes químicos do interior do estado de Pernambuco, Brasil. Concluiu-se que 93,53\% das esposas apresentaram stress, sendo 70,96\% com sintomas psicológicos, 19,35\% com sintomas físicos e 3,22\% com sintomas físicos e psicológicos. Como fontes externas de stress, foram identificadas: sobrecarga por assumir todas as responsabilidades na família, falta de apoio em relação à dependência do marido, e agressões verbais por parte dele. Quanto às internas: não perceber alternativas que ajudem na recuperação do marido, sentimento de raiva ao vê-lo alcoolizado, e tensão e preocupação quando ele sai de casa. Ficou clara, então, a necessidade de desenvolver programas de prevenção e manejo do stress para essa população.
\end{abstract}

Unitermos: dependência do álcool; família; stress.

\begin{abstract}
This research investigated the incidence of stress and its sources in alcoholics' wives by applying Lipp's Stress Symptoms Inventory and a semistructured interview in 31 women whose husbands were attended by a chemical dependents' clinic located inland of Pernambuco State, Brazil. It was concluded that $93.53 \%$ of the wives presented stress diagnosis, with psychological (70.96\%), physical (19.35\%) and both psychological and physical symptoms (3.22\%). The following external sources of stress were identified: overload feeling due to the assumption of the whole family responsibility; lack of support concerning to their husband's addiction; and verbal aggressions suffered from their husbands. In regard to internal sources: in ability to identify alternatives that can be helpful to their husband's recovery; angry feeling when they are drunk; and tension and worry when they leave home. Therefore, it has become clear the need to develop stress programs for this population which are focused on prevention and handling abilities.
\end{abstract}

Uniterms: alcohol abuse; family; stress.

O stress e seus efeitos no organismo humano têm sido o foco de inúmeras pesquisas no Brasil (Calais, 2003; Lipp \&Tanganelli, 2002;Vincentin, 2004) que buscam identificar os prejuízos e desestabilizações provocados por esse fenômeno na sociedade em geral. Há também indicação de que uma exposição prolongada a algum

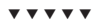

Psicóloga. Recife, PE, Brasil.

2 Universidade Católica de Pernambuco, Mestrado em Psicologia Clínica. R. do Príncipe, 526, Bloco G4, 80 andar, Boa Vista, 50050-900, Recife, PE, Brasil. Correspondência para/Correspondence to: M.C.L.A. AMAZONAS.E-mail: <crisamaz@elogica.com.br>.

3 Faculdade Frassinetti do Recife, Curso de Psicologia. Recife, PE, Brasil. 
evento estressor possa interferir no bem-estar físico, psicológico e na qualidade de vida dos sujeitos.

Os estudos que envolvem o stress têm incluído algumas pesquisas a respeito dos familiares que acompanham a doença de algum de seus membros, entre elas: O Stress em Pais de Crianças com Leucemia (Urbano, 2004), Stress nos Progenitores de Usuários de Cocaína e Crack (Vincentin, 2004), entre outros. Segundo Lipp (2000b), as desestabilizações familiares acontecem quando um dos componentes da família sofre de alguma doença, problema emocional grave ou comportamento delinqüente, como o uso de drogas, envolvimentos com roubos ou outros atos criminosos. Embora a Síndrome de Dependência do Álcool seja reconhecida como uma doença e não haja dúvidas de que a convivência com um dependente prejudique a saúde de todos os que com ele convivem, observa-se que os cuidados relacionados aos membros da sua família, em especial às esposas, não acontecem com a freqüência necessária, sendo a bibliografia sobre esse tema escassa.

O conceito de síndrome é utilizado na Medicina para designar um conjunto de sinais e sintomas, embora não seja obrigatória a presença de todos simultaneamente.

A CID - 10, critério adotado no Brasil pelo Sistema Único de Saúde (SUS), denomina Transtorno Mental e Comportamental Devido ao Uso do Álcool (F10) para indicar o tipo de substância psicoativa a que essa síndrome está associada. O tipo de transtorno relacionado ao álcool a que estamos nos referindo neste trabalho é a Síndrome de Dependência do Álcool (F10.2).

Segundo a Organização Mundial da Saúde (OMS), essa síndrome pode ser definida como um

Conjunto de fenômenos comportamentais, cognitivos e fisiológicos que se desenvolvem após repetido consumo de uma substância psicoativa, tipicamente associado ao forte desejo de tomar a droga, à dificuldade de controlar o consumo, à utilização persistente apesar de suas conseqüências nefastas, a uma maior prioridade dada ao uso de droga em detrimento de outras atividades e obrigações, a um aumento da tolerância à droga e por vezes a um estado de abstinência física. A síndrome de dependência pode dizer respeito a uma substância psi432 coativa específica (por exemplo, o fumo, o álcool ou
- Diazepam), a uma categoria de substâncias psicoativas (por exemplo, substâncias opiáceas) ou a um conjunto mais vasto de substâncias farmacologicamente diferentes (Organização Mundial da Saúde, 1993, p.74).

O DSM-IV observa alguns pontos para caracterizar a dependência da substância: maior tolerância; síndrome de abstinência; desejo persistente ou esforços malsucedidos no sentido de controlar ou reduzir o uso da substância; consumo freqüente e em maiores quantidades; atividades sociais, ocupacionais ou recreativas são abandonadas ou reduzidas em virtude do seu uso; apesar de o indivíduo ter a consciência de apresentar um problema físico ou psicológico causado pela substância, ainda assim persiste o seu consumo (Manual de Diagnóstico e Estatística de Transtornos Mentais - DSM-IV, 1995).

Além desses aspectos, como qualquer outra doença, a Síndrome de Dependência do Álcool representa uma disfunção ou inadaptação às necessidades da vida cotidiana, geralmente trazendo intensos conflitos aos sujeitos e repercutindo em todos os ambientes que o bebedor freqüenta. Muitas vezes, a companheira do portador da síndrome de dependência do álcool tende a adoecer devido às freqüentes pressões e angústias diante da expectativa constante de novos constrangimentos, agressões, medos, frustrações em virtude das recaídas, entre outras conseqüências negativas trazidas pelo álcool.

Há mulheres que passam grande parte de suas vidas na tentativa de recuperar a estabilidade de sua família, devido a alguma doença. No caso das esposas dos portadores dessa síndrome, elas se vêem, muitas vezes, obrigadas a controlar casa, filhos e vida profissional sozinhas, e ainda têm que lidar com a falta de informação, incapacidade e frustração por não conseguirem controlar a doença do marido, quase sempre se sentindo culpadas. Independentemente da teoria que explique essa síndrome, consideramos que suas conseqüências atingem não apenas o bebedor, mas também suas esposas, tornando-as vulneráveis ao stress e provocando alterações em sua estabilidade física e emocional.

Embora existam muitas definições e significados para o termo stress, tomamos como referência a definição que considera esse fenômeno como uma "reação 
psicofisiológica muito complexa que tem em sua gênese a necessidade de o organismo fazer face a algo que ameace sua homeostase interna" (Lipp, 2003, p.18). O stress pode ocorrer quando o sujeito se depara com alguma situação que, de algum modo, cause irritação, medo, excitação, ou até mesmo Ihe traga uma imensa felicidade (Lipp, 2003). O que determina se o stress irá ocorrer é a capacidade do organismo de atender as exigências daquela situação, independentemente dessas serem de natureza positiva ou negativa (Lipp \& Tanganelli, 2002).

Adotamos, nesta pesquisa, o modelo quadrifásico do stress elaborado por Lipp (2000a), segundo o qual a evolução do quadro de stress passa por algumas mudanças dependendo de quanto tempo dure o estressor. A primeira fase, denominada de "alerta", pode ser considerada a fase positiva do stress, pois o sujeito tem a capacidade de reservar energia para enfrentar a situação, além de melhorar a produtividade do indivíduo; se os estressores permanecem, o organismo tenta impedir o desgaste total de energia, entrando na fase de "resistência", que ocorre quando a pessoa tenta lidar com os estressores para manter o seu equilíbrio. Se, ainda assim, a pessoa não consegue eliminar o estressor, o organismo entra para a terceira fase denominada de "quase-exaustão"; nessa fase, algumas doenças começam a surgir. A quarta e última fase é a de "exaustão", que ocorre quando o estressor ainda está presente e esgota todas as energias do organismo do indivíduo. É nessa última fase que o sujeito iniciará uma predisposição às doenças mais graves (Lipp, 2000a).

Atualmente, tanto os homens quanto as mulheres sofrem pressões diárias, podendo acarretar stress e, conseqüentemente, sérias repercussões para a saúde (Witkin-Lanoil, 1985). Segundo Lipp (1996), estressor ou fontes de stress é tudo aquilo que provoque uma quebra na homeostase interna, que solicite uma adaptação a mudanças e que necessite que o sujeito libere sua energia para poder lidar com os eventos.

O stress pode ser originado de fontes estressoras internas e externas. As externas independem do modo de funcionamento do sujeito e podem estar relacionadas a uma mudança de emprego, acidentes ou qualquer outro evento que ocorra fora do corpo e da mente da pessoa. Os estressores internos são desencadeados pelo próprio sujeito, devido ao seu estilo de ser, seus aspectos pessoais, como timidez, ansiedade, dificuldades em expressar-se, entre outros (Lipp, 1996).

Tanganelli (2003) cita alguns fatores que podem desencadear o stress em mulheres, como, por exemplo: dedicação extrema ao trabalho ou aos filhos; viver a profissão mais como uma obrigação; ressentimentos da falta de tempo para si mesma; sua própria fisiologia e as mudanças decorrentes da vida. Algumas enfrentam o stress com um padrão de comportamento que inclui competição, esforço, impaciência, agressividade, pressa, controle e hostilidade. Essas reações reproduzem níveis mais altos de stress (Tanganelli, 2003).

Segundo Calais (2003), o stress prolongado pode tornar tanto o corpo como a mente sobrecarregados. Isso pode resultar em sintomas físicos e/ou psicológicos. Os sintomas físicos podem ser tonturas, dores de cabeça constantes, transpiração excessiva, tensão na região do pescoço, acelerações cardíacas, dores de estômago, diarréia ou prisão de ventre, irregularidades na menstruação ou a falta dela, entre outros. Ainda para essa autora, entre os sintomas psicológicos é comum a mulher sentir irritação, tensão, ansiedade, tristeza, dificuldade de concentração, até mesmo adquirir hábitos como o tabagismo e o consumo do álcool. Vale ressaltar que tanto os sintomas físicos quanto os psicológicos podem se manifestar ao mesmo tempo em um sujeito.

Todos esses sintomas acarretam sérias complicações para a saúde da mulher, para seu ambiente de trabalho e seu lar. A mulher de um portador da síndrome de dependência do álcool, quando estressada, em nada poderá colaborar para o tratamento do esposo, ao contrário, poderá tomar atitudes que agravem ainda mais a situação, tais como: ameaçar abandonar o lar, afastar-se do esposo tentando evitá-lo, embriagar-se propositalmente, agredi-lo verbalmente, entre outras (Edwards, 1999). Os efeitos causados pelo stress prolongado não se limitam ao comprometimento da saúde. O stress pode também, além de facilitar o surgimento de diversas doenças, influenciar negativamente nos demais aspectos da vida do sujeito.

Com o aumento da incidência de dependência do álcool e percebendo que seus efeitos prejudicam não apenas o sujeito que bebe, mas também a sua família como um todo, fazem-se necessários estudos abrangendo não apenas o usuário dependente do álcool, como também os outros membros da família. 
Neste artigo abordamos, especificamente, as esposas dos portadores da síndrome de dependência do álcool em relação ao nível de stress e principais fontes estressoras. A mulher, no papel de esposa, ocupa uma função relevante na conquista da abstinência, colaborando no tratamento e na reorganização do ambiente familiar. Para isso é necessário, entretanto, cuidar de sua saúde tanto física quanto psicológica. Sempre é possível aliviar a intensidade do stress e criar, no ser humano, certa resistência que pode ser aprendida por meio de técnicas de manejo do stress (Lipp, 1996). Essas são as razões que nos levaram a estudar o stress e as fontes estressoras nessas mulheres.

\section{Método}

\section{Participantes}

Foram avaliadas 31 esposas de portadores da síndrome de dependência do álcool, cujos cônjuges estavam iniciando tratamento ambulatorial numa clínica de tratamento para dependentes químicos situada em uma cidade do interior de Pernambuco. Para a escolha da amostra não levamos em consideração a idade, a profissão, o nível de escolaridade, nem a religião. Levamos em conta, no entanto, o tempo de convivência conjugal, isto é, foi exigido para compor a amostra um mínimo de três anos de convívio com o portador da síndrome. Essa exigência se baseou nos estudos de Kaplan e Sadock (1993), os quais constataram que a exposição prolongada a fatores estressores pode interferir na vida do indivíduo, ou seja, partimos da suposição de que quanto mais tempo a mulher convive com a doença do marido, mais elevado será o nível de stress.

Em relação ao tempo de casamento, 48,30\% tinham, até o momento da pesquisa, de 21 a 30 anos de casadas; 29,00\% de 3 a 10 anos; 19,30\% de 11 a 20 anos; e 3,22\% de 31 a 40 anos de relacionamento.

\section{Instrumentos}

- Inventário de Sintomas de Stress para Adultos de Lipp (ISSL)

É um instrumento que foi elaborado por Lipp, 434 validado por Lipp e Guevara (1994) e padronizado por
Lipp (2000a). A autora se baseou no modelo trifásico de stress de Hans Selye, porém acrescentou uma nova fase, a quase-exaustão, formando, assim, o modelo quadrifásico do stress, dividido em três partes. A primeira verifica a existência ou não de stress no sujeito; a segunda investiga a fase de stress em que a pessoa se encontra: alerta, resistência, quase-exaustão ou exaustão; e a terceira, a área de maior manifestação dos sintomas: física ou psicológica. Esse inventário classifica os sintomas em: físicos, psicológicos e físicos/psicológicos simultaneamente.

Para facilitar a análise dos dados obtidos, a avaliação dos resultados é feita por meio de uma tabela que transforma os dados em porcentagens.

\section{- Entrevista Semi-Estruturada}

Foi utilizado neste trabalho a entrevista semi-estruturada, que consiste em uma conversação, composta por perguntas abertas, proporcionando uma maior liberdade ao informante (Andrade, 2003). A entrevista elaborada pela pesquisadora e aplicada às participantes teve como objetivo principal colher dados sobre as fontes de stress que mais acometem essas mulheres. As questões da entrevista investigam a ocorrência de agressão física ou verbal por parte do esposo; o responsável pelas atividades que envolvem a família; se recebem ajuda de terceiros no manejo com o cônjuge; as maiores preocupações e dificuldades em decorrência da dependência do marido; o sentimento ao perceber que o esposo está alcoolizado; o sentimento quando ele sai de casa; se percebem alternativas para ajudar em sua recuperação.

Essas entrevistas foram submetidas à Análise de Conteúdo (Minayo, 1999).

Foram utilizados para a coleta de dados: um gravador de voz, 16 fitas cassete (60 minutos cada). A pesquisa foi realizada em uma clínica para tratamento de dependentes químicos que se localiza em uma cidade do interior de Pernambuco. É importante ressaltar que os dependentes estavam iniciando tratamento ambulatorial nessa clínica, e estavam acompanhados de suas esposas, que, na ocasião, foram convidadas a participar do estudo.

\section{Procedimentos}

Os encontros com as participantes ocorreram na própria clínica, em um local apropriado, onde elas 
eram recebidas de forma individual e lhes era explicado o objetivo da pesquisa e os benefícios que ela poderia proporcionar. Após essas explicações e apresentação dos instrumentos a serem utilizados, foi-lhes solicitada, pela pesquisadora, a assinatura do Termo de Consentimento Livre e Esclarecido. Nessa ocasião, informamos que as entrevistas seriam gravadas em fita cassete. Também Ihes foi dito que poderiam desistir da participação no momento que assim o desejassem, sem sofrer qualquer tipo de prejuízo.

A coleta de dados ocorreu durante os meses de dezembro/2005 e janeiro/2006 para que se pudesse atingir o número desejado de participantes.

\section{Resultados}

Os resultados obtidos no Inventário de Sintomas de Stress de Lipp (ISSL) foram analisados segundo a orientação da própria autora, ou seja, foram calculados os percentuais: de mulheres que estavam estressadas, das fases em que se encontravam, e dos sintomas mais freqüentes. Foi avaliado o nível de significância da presença de stress na amostra por meio do teste do qui-quadrado (Marconi \& Lakatos, 2002), sendo o nível exigido de $5 \%$. Uma vez constatado que a participante se encontrava estressada, buscou-se detectar, na entrevista, as possíveis fontes estressoras internas: crenças relacionadas à doença do cônjuge, medo de que os filhos se tornem iguais aos pais; e as externas: situações vividas em função da síndrome do marido, por exemplo, agressões físicas e/ou verbais. Para o tratamento das entrevistas, utilizamos a Análise de Conteúdo (Minayo, 1999), que é a técnica mais difundida para investigar o conteúdo das comunicações de massas, por meio de uma classificação em categorias, dos elementos da comunicação. Nela, o conteúdo da entrevista é analisado por categorias sistemáticas, determinadas a partir do conteúdo das próprias entrevistas, que levam a resultados quantitativos (Marconi \& Lakatos, 2002).

Por essa técnica, foram identificadas e categorizadas as fontes de stress externas e internas mais freqüentes nas esposas de dependentes do álcool. Categoria é a classe, o grupo ou o tipo em uma série classificada, que por sua vez são elementos exclusivos e incluem todas as probabilidades importantes, evitando possíveis equívocos nas respostas. O que caracteriza cada categoria são os tipos de respostas que estão relacionadas à presente pergunta (Marconi \& Lakatos, 2002).

\section{Discussão}

\section{Incidência de stress e sintomatologia mais freqüente}

Das 31 mulheres que participaram da pesquisa, 29, ou seja, 93,53\% apresentaram stress, variando a fase em que se encontravam. Para analisarmos o nível de significância em relação à ocorrência de stress, utilizamos o teste estatístico qui-quadrado (Marconi \& Lakatos, 2002), o que nos demonstrou que a ocorrência de stress na amostra pesquisada é significativa ao nível de 1,00\%. A maioria (67,70\%) se encontrava na fase de resistência, $12,90 \%$ na fase de exaustão e, nas fases de alerta e de quase-exaustão, encontramos o mesmo percentual (6,45\% da amostra em cada fase).

Os estudos sobre a Síndrome de Dependência do Álcool afirmam que a família de um dependente é freqüentemente sobrecarregada pelos problemas advindos do uso do álcool (Dalgalarrondo, 2000; Edwards, 1999). Isso pode ser o motivo da marcante presença de stress entre as mulheres que se encontram, na maioria, nas fases de resistência e exaustão.

Sabemos que qualquer situação que exija do sujeito esforço para se adaptar pode ocasionar o stress. A esposa do portador dessa síndrome, por freqüentemente presenciar o cônjuge em estado de embriaguez, tem o seu cotidiano invadido por toda sorte de imprevistos e preocupações, o que tende a lhe propiciar um processo de esgotamento (Edwards, 1999).

Além do conhecimento do nível de stress nessas mulheres, esta pesquisa também teve o objetivo de verificar os seus sintomas mais freqüentes. Para isto, também utilizamos o Inventário de Sintomas de Stress para Adultos de Lipp (ISSL).

Nesta amostra observamos uma alta freqüência de sintomas psicológicos (70,96\%), seguidos dos sintomas físicos $(19,35 \%)$ e dos sintomas físicos e psicológicos conjuntamente (3,22\%). Esses dados 
demonstram que, dentre as participantes que apresentaram o stress, a área mais afetada foi a psicológica, isto é, elas se encontram mais "vulneráveis psicologicamente". Nossos resultados vêm ao encontro dos achos de Edwards (1999): a convivência com um esposo que apresente um quadro de sintomas característicos de dependência do álcool pode acarretar, nas mulheres, problemas de ordem emocional (Figura 1).

Na análise do ISSL, os sintomas psicológicos mais mencionados pelas participantes foram os seguintes: "pensar constantemente em um só assunto" (83,8\%); "irritabilidade excessiva" (77,4\%); e "diminuição da libido" (58,0\%). Considerando os problemas diários enfrentados especialmente pela esposa de um portador da síndrome de dependência do álcool, é possível compreender a alta incidência de stress entre as participantes. Sabe-se que pessoas sob um stress excessivo geralmente voltam o seu pensamento para aquele assunto que está lhe causando stress. Lipp e Malagris (2001) afirmam que, muitas vezes, a pessoa que pensa e fala constantemente em um só assunto não percebe estar com a atenção direcionada para um só tema. No caso dessas mulheres, é possível que elas fixem o pensamento em episódios constrangedores e difíceis provocados pela enfermidade do marido e, como mencionado anteriormente, muitas vezes não se dêem conta de que estão absorvidas por essa problemática.

A "irritabilidade excessiva"foi o segundo sintoma psicológico mais mencionado. De acordo com Lipp e Malagris (2001), é um sintoma muito freqüente em pessoas estressadas como conseqüência do desgaste

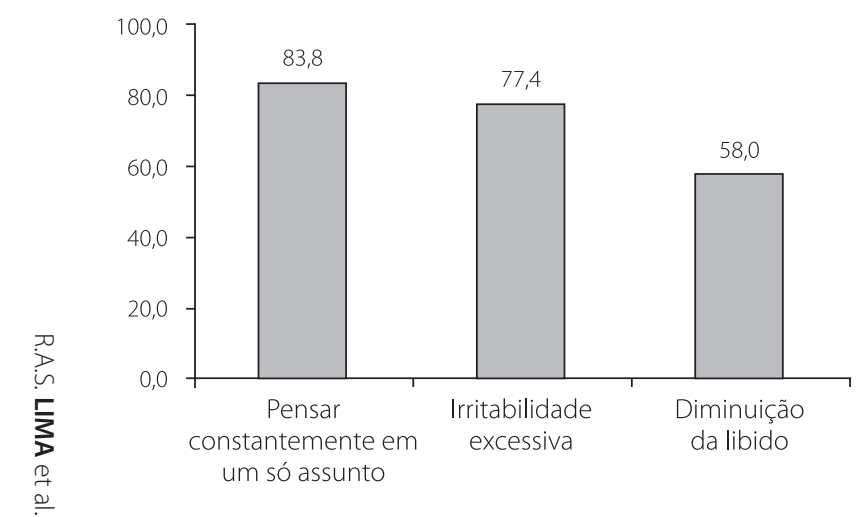

Figura 1. Sintomas psicológicos. do organismo, fazendo com que qualquer provocação gere uma reação de impaciência.

O terceiro sintoma mais mencionado pelas participantes foi a "diminuição da libido", um sintoma característico da fase de resistência, pois, nessa fase, o cansaço do sujeito faz cessar ou diminuir seu interesse pelo sexo. Isto é compatível com nossos resultados, uma vez que as participantes, em sua maioria, encontravam-se na fase de resistência.

Segundo McGoldrick (1995), as mulheres geralmente estão mais expostas às instabilidades do que os homens e, portanto, mais vulneráveis ao stress devido ao envolvimento emocional que estabelecem com quem as cerca. Esse fator pode ser a possível justificativa para a maior freqüência de sintomas psicológicos nas mulheres de dependentes do álcool.

\section{Fontes externas de stress}

Na análise das entrevistas, observamos estressores externos e internos. Os externos foram: a mulher, como a responsável por tudo o que diz respeito à família (80,6\%); o fato de não receber nenhum tipo de ajuda no manejo com o esposo $(79,6 \%)$ e sofrer agressões verbais $(38,7 \%)$.

Em relação às obrigações com suas famílias, as responsabilidades mencionadas pelas esposas foram as seguintes: educação dos filhos, cuidados com a casa, entre outras. Segundo Payá e Figlie (2004), esses aspectos fazem parte de um dos estágios que a família do portador dessa síndrome enfrenta, devido ao alto nível de desorganização que ela alcança. $O$ indivíduo que porta a síndrome de dependência do álcool se abstém de assumir qualquer tipo de responsabilidade e a inversão de papéis e funções se torna comum. As responsabilidades extras que sua mulher assume também são confirmadas como um dos fatores muito freqüentes na situação clínica (Bertolote, 1997). Quando questionadas sobre quem assume mais responsabilidade pelo lar ou pela família, algumas mulheres respondem:

E64 - "Eu, em tudo. Eu sou o homem e a mulher da casa, como diz a história".

436 A letra E está relacionada à esposa e o número que a acompanha refere-se à identificação. 
A escassez do apoio para o manejo com o esposo é também um fato mencionado pelas participantes que, muitas vezes, tende a provocar o stress. Quanto a isto, Edwards (1999) diz que as mulheres geralmente lidam sozinhas com as situações mais difíceis causadas pela enfermidade do esposo. Wilson (1997) diz que as companheiras desses homens geralmente experimentam o abandono por parte dos familiares, vizinhos e demais componentes da sociedade. Sobre esse aspecto, uma das participantes diz:

E17 - "... eu me vejo sozinha pra cuidar dele. Sozinha mesmo. Eu é que sou casada com ele, né?".

As agressões verbais são fontes externas de stress também muito mencionadas por nossas participantes. Sobre isso, Wilson (1997) diz que esses acontecimentos são muito freqüentes nesses lares: humilhações, ameaças, o ato de ridicularizar, entre outros. A esse respeito, obtivemos diversos relatos. Entre eles, selecionamos os dois que se seguem para ilustrar este tópico:

E21 - "Verbal, Ave Maria, nem conto".

E30 - "Ele não é violento fisicamente não, só assim, em palavras, maltrata ele e a gente que convive".

Essas fontes externas de stress mencionadas foram constatadas na maioria das entrevistas das esposas e também são comumente identificadas pelos estudiosos dessa síndrome como situações típicas de um lar em que um dos cônjuges é portador da síndrome de dependência do álcool (Payá \& Figlie, 2004; Wilson, 1997).

\section{Fontes internas de stress}

No que diz respeito aos estressores internos, constatamos: o fato de não perceberem outras alternativas para ajudar na recuperação do esposo (54,8\%); o sentimento de raiva ao ver o esposo alcoolizado (54,8\%); a maior preocupação e dificuldade com os filhos (51,6\%); tensão e preocupação quando o esposo sai de casa (41,8\%).

O fato de as mulheres não perceberem alternativas para ajudar na recuperação do marido faz parte de uma seqüência de estágios das reações das esposas dos portadores da síndrome de dependência do álcool. Para Edwards (1999), no início há uma tendência do cônjuge a não admitir que a bebida é um problema em sua vida. Após esse período, a mulher entra na fase em que não percebe alternativas para a recuperação do marido; não identifica estratégias para evitar ou amenizar o uso do álcool de seu companheiro. Para Payá e Figlie (2004), essa percepção de que não existem alternativas para a recuperação do esposo faz com que a mulher acredite que a síndrome de dependência do álcool seja o "destino da sua família"(p.343). Esse tipo de percepção tende a provocar um sentimento de desesperança nessas mulheres e, possivelmente, esse seja um fator importante para o aparecimento do stress entre elas. Como revelam os relatos:

E13 - "Vai ser sempre essa luta, né?".

E14 - "Quando ele bebia direto, ficava sem esperança de que nada ia melhorá-lo, acreditava que era a vida que ele escolheu e pronto. Então, deixei de mão, no dia em que ele quiser deixar, ele deixa".

E16 - "Já me senti tão desesperada nesse mundo que até já tentei suicídio. Pedia sempre uma solução a Deus e não resolveu...."

A raiva é um dos principais sentimentos experimentados pelos familiares que convivem com um portador da síndrome de dependência do álcool (Payá \&Figlie, 2004). Nesta amostra, as esposas relataram sentir raiva ao perceberem que seus maridos estão alcoolizados. Esse sentimento tem alta capacidade de gerar stress e, em muitas situações, surge com grande intensidade (Lipp, 2005), como demonstram os relatos a seguir:

E15 - "Ele passa noites fora de casa, chega de madrugada, bêbado. Sinto tanto ódio, raiva. Eu não consigo me controlar...".

E21- "Dá vontade de deixar ele no canto e desaparecer pra não ver a cara, dá raiva".

As esposas relataram ter medo de que seus filhos se tornassem dependentes do mesmo modo que os pais, o que denota uma maior preocupação e dificuldade com os filhos. Nesta pesquisa, essas preocupações e dificuldades são consideradas um pensamento disfuncional, pois não correspondem à realidade atual, ou seja, seus filhos até o momento não apresentaram indícios de uso do álcool. Essa preocupação constante com o futuro dos filhos, além de causar stress, impede que essas mulheres adotem ações mais adequadas no 
sentido de evitar que os filhos sigam o caminho dos pais. Sobre esse tópico, temos:

E18 - "Os filhos podem querer seguir, porque se ele vai a um bar e leva um filho, ele vai achar bonito e pode futuramente fazer isso".

E20 - "Tenho medo que meu menino faça o mesmo".

Outro considerável estressor interno diz respeito à tensão e à preocupação que a esposa sente quando seu companheiro está fora de casa. Nesta pesquisa, as mulheres relataram expectativas sobre a maneira como ele voltará para casa. Ficam tensas e preocupadas por não saber se chegará alcoolizado ou não, agressivo, se sofrerá algum acidente, entre outras possibilidades. Segundo Teles (1993), a tensão pode ser considerada como um estado de prontidão do organismo para agir, e as pessoas que vivem sob tensão constante e não encontram meios de relaxar estão predispostas a danos físicos, entre outros prejuízos, como demonstra a frase seguinte:

E 16 - "Eu já entro em suspense, né? O que será que ele vai fazer? Como vai chegar? Aonde vai? Como vai voltar?".

\section{Considerações Finais}

Este estudo aponta um alto índice de stress nas esposas de portadores da síndrome de dependência do álcool, sugerindo a necessidade de trabalhos de intervenção para o controle do stress nessas mulheres.

Além disso, as fases de stress em que elas, predominantemente, se encontram (resistência e exaustão) justificam uma preocupação não apenas com seu estado de saúde, física e psíquica, mas também com as repercussões em todo o ambiente familiar, principalmente sobre os filhos. Esses resultados demons-tram um alto índice de stress patológico e a sobrecarga que o cotidiano dessas esposas apresenta.

Foi possível identificar, pelas análises das entrevistas, as principais fontes estressoras internas e externas de stress das esposas desses dependentes. Entre os estressores internos encontramos cognições e sentimentos negativos que dificultam as buscas por tentativas de solução do problema do esposo, contribuindo para o agravamento do stress. Os estressores internos mais encontrados foram: a não percepção de alternativas para ajudar na recuperação do companheiro; o sentimento de raiva ao perceberem seus maridos alcoolizados; as preocupações e dificuldades decorrentes do medo que elas têm de que seus filhos se tornem dependentes do álcool futuramente, bem como as tensões e preocupações experimentadas ao perceberem que os seus cônjuges saíram de casa.

Outros fatores que contribuem para o stress nessas mulheres referem-se aos estressores externos: responsabilidades em relação aos aspectos familiares; falta de apoio de outras pessoas no manejo com o esposo e os sofrimentos constantes devido às agressões verbais dos maridos. Tais situações fogem do controle dessas mulheres e também podem provocar desestabilizações quanto a aspectos físicos e psicológicos.

A partir dos conhecimentos acerca dos prejuízos que a dependência do álcool de um ente próximo acarreta em uma família - no caso desta pesquisa, a esposa desse homem -, podemos compreender melhor as conseqüências negativas advindas dessa síndrome.

Tais resultados, verificados pelos instrumentos utilizados, apontam para a necessidade de desenvolvimento de técnicas de controle do stress nessas mulheres. Acreditamos que este trabalho represente um início não apenas para que mais pesquisas sejam elaboradas para essa população, mas, principalmente, para auxiliar os profissionais que lidam com ela a desenvolver programas de atendimento que minimizem os prejuízos sobre a vida dessas mulheres e de todo o seu entorno. Dessa forma, as esposas de portadores da síndrome de dependência do álcool poderiam contribuir de forma positiva para o tratamento dos maridos e alcançariam uma melhor qualidade de vida.

É importante ressaltar que os dados da presente pesquisa foram extraídos de uma amostra em uma cidade do interior de Pernambuco, Nordeste do Brasil, a qual possui valores e cultura próprios. Nesse sentido, os resultados não podem ser generalizados, porém ajudam a compreender a nossa realidade quanto à temática em questão. Sugere-se a realização de outras pesquisas ou a repetição do estudo em outras regiões brasileiras a fim de constatar ou não os nossos achados. 


\section{Referências}

Andrade, M. A. (2003). Introdução à metodologia do trabalho científico (6a. ed.) São Paulo: Atlas.

Bertolote, J. M. (1997). Conceitos em alcoolismo. In: J. M. Bertolote (Ed.), Alcoolismo hoje (pp.198-210). Porto Alegre: Artes Médicas.

Calais, S. L. (2003). Diferenças entre homens e mulheres na vulnerabilidade ao stress. In M. E. N. Lipp (Ed.), Mecanismos neuropsicofisiológicos do stress: teoria e aplicações clínicas (pp.87-88). São Paulo: Casa do Psicólogo.

Dalgalarrondo, P. (2000). Psicopatologia e semiologia dos transtornos mentais. Porto Alegre: Artmed.

Edwards, G. (1999). O tratamento do alcoolismo: um guia para profissionais da saúde. Porto Alegre: Artes Médicas.

Kaplan, H. I., \& Sadock, B. J. (1993). Compêndio de psiquiatria: ciências comportamentais e psiquiatria clínica. Porto Alegre: Artes Médicas Sul.

Lipp, M. E. N. (1996). Pesquisa sobre stress no Brasil: saúde, ocupações e grupos de risco. Campinas: Papirus.

Lipp, M. E. N. (2000a). Manual do inventário de sintomas de stress para adultos de Lipp (ISSL). São Paulo: Casa do Psicólogo.

Lipp, M. E. N. (2000b). O stress está em você (2a. ed.) São Paulo: Contexto.

Lipp, M. E. N. (2003). O modelo quadrifásico do stress. In M. E. N. Lipp (Ed.), Mecanismos neuropsicofisiológicos do stress: teoria e aplicações clínicas (pp.17-21). São Paulo: Casa do Psicólogo.

Lipp, M. E. N. (2005). Stress e o turbilhão da raiva. São Paulo: Casa do Psicólogo.

Lipp, M. E. N., \& Guevara, A. J. H. (1994). Validação empírica do inventário de sintomas de stress. Estudos de Psicologia (Campinas), 11 (3), 43-49.

Lipp, M. E. N., \& Malagris, L. N. (2001). Manejo do estresse. In B. Rangè (Ed.), Psicoterapia comportamental e cognitiva: pesquisa, prática, aplicações e problemas (pp.279-292). São Paulo: Pleno.

Lipp, M. E. N., \& Tanganelli, M. S. (2002). Stress e qualidade de vida em magistrados da Justiça do Trabalho: diferenças entre homens e mulheres. Psicologia: Reflexão e Crítica, 3 (15), 537-548.
Manual Diagnóstico e Estatística de Transtornos Mentais. (1995) (4th ed.). (DSM-IV). Porto Alegre: Artes Médicas Sul.

McGoldrick, M. (1995). As mulheres e o ciclo de vida familiar. In B. Carter \& McGoldrick (Eds), As mudanças no ciclo de vida familiar (pp.30-64). Porto Alegre: Artes Médicas.

Marconi, M. A., \& Lakatos, E. M. (2002). Técnicas de pesquisa: planejamento e execução de pesquisas, amostragens e técnicas de pesquisas, elaboração, análise e interpretação de dados. São Paulo: Atlas.

Minayo, M. C. S. (1999). O Desafio do conhecimento: pesquisa qualitativa em saúde (6a. ed.). São Paulo: Abrasco.

Organização Mundial de Saúde. (1993). Classificação de transtornos mentais e de comportamento da CID-10. Porto Alegre: Artes Médicas Sul.

Payá, R., \& Figlie, N. B. (2004). Abordagem familiar em dependência química. In B. N. Figlie, S. Bordin \& R. Laranjeira. Aconselhamento em dependência química (pp.339-358). São Paulo: Roca.

Tanganelli. M. S. (2003). O treino do controle do stress aplicado a mulheres. In M. E. N. Lipp (Ed), Mecanismos neuropsicofisiológicos de stress: teoria e aplicações clínicas (pp.205-210). São Paulo: Casa do Psicólogo.

Teles, M. L. S. (1993). O que é stress. São Paulo: Brasiliense.

Urbano, M. F. G. (2004). Stress e qualidade de vida dos pais de crianças com leucemia e o stress da criança. In M. E. N. Lipp (Ed.), O stress no Brasil: pesquisas avançadas (pp.105-113). Campinas: Papirus.

Vincentin, V. F. (2004). Stress e qualidade vida dos progenitores de usuários de cocaína e crack. Dissertação de mestrado não-publicada, Pontifícia Universidade Católica de Campinas.

Wilson, M. (1997). Conviver com quem bebe. São Paulo: Summus.

Witkin-Lanoil, G. (1985). A síndrome do stress feminino: como reconhecê-la e viver com ela. Rio de Janeiro: Imago.

Recebido em: 29/1/2007

Versão final reapresentada em: 15/6/2007

Aprovado em: 13/7/2007 
